\title{
Ultrasound: A poor diagnostic test for cryptorchidism
}

\section{Gregory Tasian, MD, MSc, MSCE}

Center for Clinical Epidemiology and Biostatistics, University of Pennsylvania Perelman School of Medicine; Division of Urology and Center for Pediatric Clinical Effectiveness, The Children's Hospital of Philadelphia

See related article on page 387.

Cite as: Can Urol Assoc J 2015;9 (11-12):391. htrp://dx.doi.org/10.5489/cuai.3507

Published online December 14, 2015.

$\mathrm{T}$ his prospective, observational study by Wong et al determined the diagnostic performance of ultrasound among boys referred to a tertiary hospital with palpable undescended testes. This study builds upon the extensive body of evidence that ultrasound is a poor diagnostic test for cryptorchidism. ${ }^{1}$ At best, ultrasound is a needless expense. At worst, ultrasound delays definitive surgical care. ${ }^{2}$ The recent American Urological Association guidelines on cryptorchidism also state that that ultrasound is unnecessary for boys with undescended testes. ${ }^{3}$

Ultrasound is unnecessary because physical exam can reliably differentiate retractile testes from undescended testes and determine if the testis is palpable or not. Despite evidence to the contrary and guidelines that recommend against using ultrasound for the pre-surgical evaluation of cryptorchidism, ultrasound remains a commonly used diagnostic imaging study for children with non-scrotal testes.
Future studies should determine the barriers to adherence to guidelines and identify interventions (e.g., Physician Quality Reporting System [PQRS] measures, clinical decision support) that decrease inappropriate ultrasound use.

Competing interests: Dr. Tasian was supported by K23-DK106428 from the National Institutes of Health (NIH)/National Institute of Diabetes and Digestive and Kidney Diseases (NIDDK). The NIH and NIDDK had no role in the design and conduct of the study; collection, management, analysis, and interpretation of the data; and preparation, review, or approval of the manuscript. The views expressed in this article are those of the authors and do necessarily represent the official view of the NIDDK or NIH.

\section{References}

1. Tasian GE, Copp HL. Diagnostic performance of ultrasound in nonpalpable cryptorchidism: A systematic review and meta-analysis. Pediatrics 2011;127:119-28. http://dx.doi.org/10.1542/peds.2010-1800

2. Kanaroglou $\mathrm{N}$, $\mathrm{To} \mathrm{T}$, Zhu J, et al. Inappropriate use of ultrasound in management of pediatric cryptorchidism. Pediatrics 2015;136:479-86. http://dx.doi.org/10.1542/peds.2015-0222

3. Kolon TF, Herndon CD, Baker LA, et al. Evaluation and treatment of cryptorchidism: AUA guideline. J Urol 2014;192:337-45. http://dx.doi.org/10.1016/i.juro.2014.05.005

Correspondence: Dr. Gregory Tasian, University of Pennsylvania Perelman School of Medicine; TasianG@email.chop.edu. 